Shaul Cohen MD, ${ }^{*}$ David Amar MD, $\dagger$

Carol B. Pantuck BA, $\ddagger$ Eugene J. Pantuck MD, $\ddagger$

Evan J. Goodman MD, ${ }^{*}$ Denis H.Y. Leung PhD $\dagger$

\title{
Epidural analgesia for labour and delivery: fentanyl or sufentanil?
}

Purpose: The highly lipid soluble opioids, fentanyl and sufentanil, are used in combination with local anaesthetics with/ without epinephrine to provide epidural analgesia during labour and delivery. Our aim was to determine whether either opioid was superior when used with low dose local anaesthetic.

Methods: In a double-blind study patients were randomized to two epidural infusion groups: Group $I(n=50)$ fentanyl 2 $\mu \mathrm{g} \cdot \mathrm{ml}^{-1}$ with bupivacaine $0.015 \%$ and epinephrine $2 \mu \mathrm{g} \cdot \mathrm{ml}^{-1}$, Group II $(n=50)$ sufentanil $1 \mu \mathrm{g} \cdot \mathrm{ml}^{-1}$ with bupivacaine $0.015 \%$ and epinephrine $2 \mu \mathrm{g} \cdot \mathrm{ml}^{-1}$. Following a $20 \mathrm{ml}$ bolus of the study solution an infusion was started at $10 \mathrm{ml} \cdot \mathrm{h}^{-1}$.To achieve analgesia patients could receive two boluses of $5 \mathrm{ml}$ of the study solution and if analgesia was still inadequate, a further $5 \mathrm{ml}$ bupivacaine $0.25 \%$ was used. Pain and overall satisfaction were assessed with a 10-point visual scale. Plasma samples obtained from the mother at the time the infusion was discontinued and from the umbilical cord vein at delivery were assayed to determine opioid concentration.

Results: Pain scores were greater for Group I than for Group II patients throughout the first and second stages of labour ( $P$ $=0.002$ ). More patients in Group I (42\%) requested a dose of bupivacaine $0.25 \%$ than in Group $I I(6 \%)(P<0.0001)$ and the total dose of bupivacaine given to Group I patients was greater than that of Group II, $26.0 \pm 22.0 \mathrm{mg} v \mathrm{vs} .13 .4 \pm 12.6$ $m g, P=0.005$. There were no differences with respect to first or second stage duration, incidence of side effects, infusion

\section{Key words}

ANAESTHETIC TECHNIQUES: epidural; ANALGESICS: fentanyl, sufentanil; PAIN: labour, delivery.

From the Departments of Anesthesiology, ${ }^{*}$ Albert Einstein College of Medicine, Bronx, New York, †Memorial SloanKettering Cancer Center and $\ddagger$ Columbia University College of Physicians and Surgeons, New York, New York, USA.

Address correspondence to: Dr. David Amar, Department of Anesthesiology and Critical Care Medicine, Memorial Sloan-Kettering Cancer Center, 1275 York Avenue, New York, NY 10021.

Phone: (212) 639-8118. Fax (212) 772-8646.

E-mail: AmarD @ MSKCC.ORG

Accepted for publication 17th November, 1995. duration, outcome of labour or neonatal Apgar scores. There was no opioid accumulation in either maternal or foetal blood. Conclusion: Epidural opioid infusion with very low dose bupivacaine (0.015\%) achieved an overall high level of patient satisfaction in both groups without serious maternal or neonatal side effects. At the fentanyl-to-sufentanil ratio used here patients receiving sufentanil had lower pain scores and substantially fewer patients required bupivacaine rescue.

Objectif: Les morphiniques hautement liposolubles comme le fentanyl et le sufentanil sont utilisés avec les anesthésiques locaux pour procurer l'analgésie épidurale pendant le travail et l'accouchement avec ou sans épinéphrine. Cette étude visait à déterminer lequel des deux morphiniques était supérieur lorsqu'on l'associait à un anesthésiques local à faible dose. Méthodes: L'étude randomisée et en double aveugle incluait deux groupes: le groupe $I(n=50)$ avait reçu du fentanyl $2 \mu \mathrm{g} \cdot \mathrm{ml}^{-1}$ et de la bupivacaïne $0,015 \%$ avec épinéphrine 2 $\mu \mathrm{g} \cdot \mathrm{ml}^{-1}$ alors que le groupe $I I(n=50)$ avait reçu sufentanil $1 \mu \mathrm{g} \cdot \mathrm{ml}^{-1}$ et bupivacaïne 0,015 avec épinéphrine $2 \mu \mathrm{g} \cdot \mathrm{ml}^{-1}$. Après un bolus de $20 \mathrm{ml}$ de la solution à l'étude, une perfusion était débutée au rythme de $10 \mathrm{ml} \cdot \mathrm{h}^{-1}$. Pour compléter l'analgésie, les patientes pouvaient recevoir deux bolus de $5 \mathrm{ml}$ de la solution à l'étude. Si l'analgésie était toujours insuffisante, une dose additionnelle de $5 \mathrm{ml}$ de bupivacaïne $0,25 \%$ était administrée. La douleur et le degré de satisfaction étaient évalués sur une échelle visuelle de dix points. Des échantillons de plasma maternal à l'arrêt de la perfusion et du cordon ombilical à l'accouchement ont été analysés pour déterminer la concentration du morphinique.

Résultats: Quant à la douleur, les scores ont été plus élevés dans le groupe I que dans le groupe II pendant le premier et le deuxième stage du travail $(P=0,002)$. Plus de patients du groupe I (42\%) ont eu besoin de bupivacaïne $0,25 \%$ que dans le groupe II $(6 \%)(P<0,001)$ et la dose totale de bupivacaïne administrée aux patientes du groupe $I$ a été plus élevée que dans le groupe II, 26,0 $\pm 22,0 \mathrm{mg}$ vs 13,3 $\pm 12,6 \mathrm{mg}, P=$ 0,005 . En ce qui concerne la durée du premier et du deuxième stage du travail, la différence était nulle, ainsi que l'incidence des effets secondaires, la durée de la perfusion, l'évolution du travail ou les scores sur l'échelle d'Apgar. On n'a pas noté d'accumulation de morphinique dans le sang maternel ni dans le sang foetal.

Conclusion: Avec une perfusion de morphinique associée à de 
très faibles doses de bupivacaïne $(0,015 \%)$, en général, le degré élevé de satisfaction a été élevé dans les deux groupes, sans effets secondaires maternels et foetaux importants. Si on compare le fentanyl au sufentanil, les patientes qui recevaient du sufentanil ont rapportés pour la douleur des scores inférieurs et beaucoup moins de patientes ont eu besoin de bupivacaïne en supplément.

Low concentrations of highly lipid soluble opioids and local anaesthetics administered by epidural infusion have been shown to provide satisfactory analgesia during labour and delivery. ${ }^{1-7}$ The addition of bupivacaine $0.04 \%$ to fentanyl $1.7 \mu \mathrm{g} \cdot \mathrm{ml}^{-1}$ provided satisfactory analgesia for labour and allowed some patients to ambulate. ${ }^{2}$ In a study using bupivacaine $0.03 \%$ in combination with fentanyl $2.0 \mu \mathrm{g} \cdot \mathrm{ml}^{-1}$ administered by patientcontrolled epidural infusion for pain relief after Caesarean delivery we found that approximately $50 \%$ of patients experienced lower extremity sensory loss. ${ }^{8}$ In subsequent studies we found that we could provide highly satisfactory analgesia with comparably low doses of fentanyl (2-3 $\left.\mu \mathrm{g} \cdot \mathrm{ml}^{-1}\right)$ without producing lower extremity sensory loss by adding bupivacaine $0.01-$ $0.015 \%$ and epinephrine $0.5-1 \mu \mathrm{g} \cdot \mathrm{ml}^{-1}$ to the infusion. ${ }^{9,10}$

The present study was designed to compare epidural fentanyl with sufentanil, combined with bupivacaine $0.015 \%$ and epinephrine $2 \mu \mathrm{g} \cdot \mathrm{ml}^{-1}$ with regard to quality of analgesia for labour and delivery, effect on neonatal outcome and opioid accumulation in maternal/foetal blood. Although it is assumed that to achieve comparable analgesia, the dose of fentanyl is five to ten times than that of sufentanil, ${ }^{11,12}$ this has not been our experience using these drugs combined with a very low dose bupivacaine and epinephrine in obstetric patients. The ratio of fentanyl to sufentanil used in this study, 2:1, was selected because we had found it to be approximately equianalgesic in a previous study ${ }^{10}$ which compared the ability of these drugs combined with low dose bupivacaine and epinephrine to provide pain relief after Caesarean delivery and because it is consistent with our clinical experience using these drug combinations in labouring women.

\section{Methods}

This study was approved by the Institutional Review Board of the Albert Einstein College of Medicine and written informed consent was obtained from each patient. One hundred ASA physical status I-II parturients requesting epidural block for uncomplicated active labour and delivery of a term singleton foetus were studied. Patients with a contraindication to epidural analge- sia or those with a complicated obstetric history were excluded.

Each patient received an infusion of $0.3 \mathrm{~L}$ lactated Ringer's solution iv. Lumbar epidural block was established by injecting a test dose of $3 \mathrm{ml}$ of 2-chloroprocaine $3 \%$ followed by $20 \mathrm{ml}$ bolus of the study solution via a catheter placed at the $\mathrm{L}_{3-4}$ interspace. All epidural bolus doses were administered immediately after a uterine contraction. During labour, the patients were maintained supine with left uterine displacement and, as is customary in our institution, did not ambulate. The foetal heart rate was monitored by continuous transabdominal Doppler ultrasound. No patient received other opioids or sedatives during this treatment.

Patients were allocated randomly, by the use of a previously generated table of random numbers to one of two epidural infusion groups: Group I $(n=50)$ fentanyl $2 \mu \mathrm{g} \cdot \mathrm{ml}^{-1}$ with bupivacaine $0.015 \%$ and epinephrine 2 $\mu \mathrm{g} \cdot \mathrm{ml}^{-1}$, Group II $(n=50)$ sufentanil $1 \mu \mathrm{g} \cdot \mathrm{ml}^{-1}$ with bupivacaine $0.015 \%$ and epinephrine $2 \mu \mathrm{g} \cdot \mathrm{ml}^{-1}$. The solutions used had been prepared and placed in $100 \mathrm{ml}$ coded bags by a study physician. Neither the investigator involved in the management and assessment of the patient nor the patient was aware of which solution was being given. Following the $20 \mathrm{ml}$ bolus of the study solution, the epidural catheter was connected to a Medfusion pump (Medfusion Inc., Duluth; GA) and each patient received an initial infusion at the rate of 10 $\mathrm{ml} \cdot \mathrm{hr}^{-1}$. Every hour, or sooner if requested, the investigator evaluated the patient for side effects and the quality of analgesia. Pain intensity was assessed using a 10point visual scale $(0=$ no pain, $10=$ worst pain ever experienced). First stage satisfaction, second stage satisfaction, and overall satisfaction with the infusion were assessed by the patient using a 10 -point scale $(0=$ no satisfaction, $10=$ best satisfaction). Patients were questioned about the incidence of pruritus, sedation, nausea and vomiting using a three-point scale $(1=$ mild, $2=$ moderate, 3 = severe). The investigator increased or decreased the infusion rate by $2 \mathrm{ml} \cdot \mathrm{hr}^{-1}$ and, if needed, administered up to two additional $5 \mathrm{ml}$ boluses of the study solution, to provide a pain score $<3$. If analgesia was not adequate, patients could receive one $5 \mathrm{ml}$ bolus of bupivacaine $0.25 \%$. The decisions to discontinue the infusion and whether to administer, at the time of delivery, a supplemental "perineal dose" (10 $\mathrm{ml}$ bupivacaine $0.25 \%$ ) to provide perineal anaesthesia were made by the staff anesthesiologist and by the obstetrician who was also blinded to the solution being used. Following the initiation of epidural block, the patient's vital signs were determined at one-minute intervals for $15 \mathrm{~min}$ by an automated blood pressure machine and subsequently at 15 -min intervals by a nurse. Maternal hypotension 
was defined as a decrease in systolic arterial pressure of $\geq 20 \%$ or to $90 \mathrm{mmHg}$ with the patient supine and with left uterine displacement.

Plasma samples, for determination of opioid concentration were obtained from arbitrarily selected patients from each group. Maternal venous blood samples were obtained, at the time of the discontinuation of the epidural infusion, from an antecubital vein of the arm contralateral to that with an intravenous infusion. Blood samples were obtained from the umbilical cord vein at the time of delivery. After separation by centrifugation, plasma samples were stored at $-20^{\circ} \mathrm{C}$ until analysis. Plasma concentrations of fentanyl ${ }^{13}$ and sufentanil ${ }^{14}$ were determined using a radioimmunoassay (RIA-kit Research Diagnostics, Flanders, New Jersey 07836). The fentanyl assay has a limit of detection of 0.1 $\mathrm{ng} \cdot \mathrm{ml}^{-1}$ and a coefficient of variation of $6.0 \%$; the corresponding values for the sufentanil assay are 0.05 $\mathrm{ng} \cdot \mathrm{ml}^{-1}$ and $7.0 \%$, respectively.

Data are given as mean \pm S.D. unless otherwise indicated. Continuous data were analyzed with Student's $t$ test or Wilcoxon rank sum test and categorical data with Chi-square or Fisher's exact test. A trend test was used for ordered categorical data (satisfaction scores). A $P$ value of less than 0.05 was considered significant.

\section{Results}

There were no differences between the groups with respect to age, height, weight, parity, or in labour and delivery characteristics (Table I). The incidence of vaginal or Caesarean delivery was not different between the groups (Table II). The upper sensory thoracic level for Group I T $8.7 \pm 0.2$ was slightly higher than for Group II T $8.3 \pm 0.2(P<0.05)$. The lower sensory lumbosacral level did not differ between the groups. Pain scores for the first and second stages of labour were greater for Group I than for Group II patients $(P<$ 0.002 ) (Table III). Second stage satisfaction was lower in Group I patients when compared with Group II ( $P=$ 0.001 , Table IV).

Infusion durations for Groups I and II did not differ and were $5.3 \pm 0.5 \mathrm{hr}$ and $4.8 \pm 0.4 \mathrm{hr}$, respectively. The average infusion rate was greater for Group I than for Group II $(P<0.01)$ and was $15.3 \pm 0.6 \mathrm{ml} \cdot \mathrm{hr}^{-1}$ and 12.7 $\pm 0.5 \mathrm{ml} \cdot \mathrm{hr}^{-1}$ respectively. The percentage of patients requesting additional bupivacaine rescue during the infusion was higher for Group I (42\%) than for Group II $(6 \%)(P<0.0001)$. Total bupivacaine received was greater $(P=0.005)$ for Group I than for Group II, as shown in Table $V$. The bupivacaine dose given as a study solution, was numerically but not statistically $(P=$ 0.06) greater for Group I than for Group II (Table V). The total dose of fentanyl was $205 \pm 109 \mu \mathrm{g}$ for Group I
TABLE I Labour and delivery characteristics

\begin{tabular}{lcc}
\hline & Group $I(n=50)$ & Group $I(n=50)$ \\
\hline $\begin{array}{l}\text { Nulliparous }(n) \\
\text { Cervical dilatation at onset of }\end{array}$ & $36(72 \%)$ & $38(76 \%)$ \\
$\quad$ infusion (cm) & $4.3 \pm 1.5$ & $4.0 \pm 1.8$ \\
Duration & & \\
- 1st Stage (min) & $942.9 \pm 94.9$ & $832.0 \pm 73.5$ \\
- 2nd Stage (min) & $82.0 \pm 73.5$ & $84.6 \pm 62.0$ \\
Oxytocin $(n)$ & $31(62 \%)$ & $37(74 \%)$ \\
Apgar score $\geq 7$ & & \\
$-1 \min (n(\%))$ & $45(90 \%)$ & $48(96 \%)$ \\
$-5 \min (n(\%))$ & $50(100 \%)$ & $50(100 \%)$ \\
\hline
\end{tabular}

Values are mean \pm SD unless otherwise indicated. Chi-square test was used to compare the number of patients who were nulliparous, received oxytocin or had an Apgar score $\geq 7$. Student's $t$ test was used for stage duration and cervical dilatation. There were no differences between the groups in labour and delivery characteristics.

TABLE II Delivery method

\begin{tabular}{lcc}
\hline & Group $I(n=50)$ & Group $I I(n=50)$ \\
\hline Vaginal delivery & & \\
- Spontaneous & $36(72 \%)$ & $34(68 \%)$ \\
- Instrumental & $4(8 \%)$ & $2(4 \%)$ \\
Caesarean delivery & & \\
- Failure to progress & $7(14 \%)$ & $10(20 \%)$ \\
- Foetal distress & $3(6 \%)$ & $3(6 \%)$ \\
- Chorioamnionitis & $0(0 \%)$ & $1(2 \%)$ \\
\hline
\end{tabular}

Fisher's exact test was used to analyze delivery method data. No differences between the two groups were seen.

and the total sufentanil dose was $83.3 \pm 41.6 \mu \mathrm{g}$ for Group II. The time from discontinuation of infusion to delivery did not differ between groups and was $0.99 \pm$ $1.1 \mathrm{hr}$. and $0.54 \pm 0.7 \mathrm{hr}$., respectively.

The incidence of side effects did not differ between groups (Table VI). No patient developed systolic hypotension in response to the epidural bolus or infusion. Upon questioning, no patient complained of lower extremity sensory loss or weakness. Sedation was never more than mild and no patient complained about the degree of sedation. No patient had a respiratory rate $<12$ breaths $\cdot \min ^{-1}$.

Maternal and umbilical vein plasma fentanyl concentrations were $0.28 \pm 0.04 \mathrm{ng} \cdot \mathrm{ml}^{-1}(n=16)$ and $0.18 \pm$ $0.02 \mathrm{ng} \cdot \mathrm{ml}^{-1}$ for Group I $(n=20)$, respectively. Maternal and umbilical vein plasma sufentanil concentrations were $0.11 \pm 0.02 \mathrm{ng} \cdot \mathrm{ml}^{-1}(n=13)$ and $0.09 \pm$ $0.02 \mathrm{ng} \cdot \mathrm{ml}^{-1}$ for Group II $(n=15)$, respectively. Daily review of nursing records showed no excessive somnolence or cyanosis in any newborn following discharge from the delivery room. 
TABLE III Pain scores

\begin{tabular}{|c|c|c|c|c|c|c|c|c|c|}
\hline \multirow[b]{2}{*}{ Stage of labour } & \multicolumn{4}{|c|}{ Group I } & \multicolumn{4}{|c|}{ Group II } & \multirow[b]{2}{*}{$P$ value } \\
\hline & Mean & $S D$ & Median & Range & Mean & $S D$ & Median & Range & \\
\hline First (8 hr) & 2.4 & 1.9 & 2.2 & $0-6.5$ & 1.3 & 1.3 & 0.9 & $0-5.7$ & 0.0018 \\
\hline Second ( $2 \mathrm{hr}$ ) & 3.7 & 2.5 & 3.0 & $0-9.0$ & 1.8 & 1.6 & 2.0 & $0-6.0$ & 0.0008 \\
\hline
\end{tabular}

Pain scores were averaged and analyzed separately for each stage of labour with the Wilcoxon rank sum test. Insufficient numbers of patients precluded data analysis after eight hours in the first stage, and after two hours in the second stage of labour, respectively. Group I patients had higher pain scores during the first and second stages of labour.

TABLE IV Satisfaction scores

\begin{tabular}{|c|c|c|c|c|c|c|c|}
\hline \multirow[b]{3}{*}{ Stage of labour } & \multicolumn{6}{|c|}{ Distribution of satisfaction scores } & \multirow[b]{3}{*}{$P$ value } \\
\hline & \multicolumn{2}{|l|}{$0-3$} & \multicolumn{2}{|l|}{$4-7$} & \multicolumn{2}{|l|}{$8-10$} & \\
\hline & Group I & Group II & Group I & Group II & Group I & Group II & \\
\hline First $(n)$ & 1 & 1 & 3 & 3 & 46 & 46 & 0.99 \\
\hline Second $(n)$ & 2 & 0 & 18 & 6 & 20 & 33 & $0.001^{\prime}$ \\
\hline Overall $(n)$ & 2 & 0 & 6 & 3 & 42 & 47 & 0.13 \\
\hline
\end{tabular}

Satisfaction scores (scale $0-10 ; 0=$ least satisfied, $10=$ most satisfied) were examined with the trend test and differed between the groups only during the second stage of labour when more group II patients had scores in the 4-7 range.

TABLE V Bupivacaine requirements

\begin{tabular}{lccl}
\hline Bupivacaine & Group l & Group Il & P value \\
\hline Given as study solution $(\mathrm{mg})$ & $12.2 \pm 8.2(1.9-32)$ & $9.1 \pm 6.3(2.3-28)$ & 0.06 \\
Additional 0.25\% boluses $(\mathrm{mg})$ & $8.8 \pm 11.9(0-50)$ & $1.3 \pm 5.2(0-25)$ & 0.0001 \\
Given as a perineal dose $(\mathrm{mg})$ & $5.0 \pm 10.1(0-25)$ & $3.0 \pm 8.2(0-25)$ & 0.30 \\
Total administered $(\mathrm{mg})$ & $26.0 \pm 22.0(1.9-105)$ & $13.4 \pm 12.6(2.3-46)$ & 0.005 \\
\hline
\end{tabular}

Bupivacaine requirements (mean \pm SD (range)). The Wilcoxon rank sum test was used for analysis.

TABLE VI Side effects

\begin{tabular}{|c|c|c|c|c|}
\hline & \multicolumn{2}{|c|}{ Group I } & \multicolumn{2}{|c|}{ Group II } \\
\hline & $n$ & $\%$ & $n$ & $\%$ \\
\hline Pruritus (total) & 31 & 62 & 39 & 78 \\
\hline - *Severe & 1 & 2 & 1 & 2 \\
\hline Sedation (total) & 27 & 54 & 31 & 62 \\
\hline - *Severe & 0 & 0 & 0 & 0 \\
\hline Nausea & 4 & 8 & 3 & 6 \\
\hline Vomiting & 3 & 6 & 3 & 6 \\
\hline Urinary retention & 12 & 24 & 8 & 16 \\
\hline Respiration $<12 \cdot \min ^{-1}$ & 0 & 0 & 0 & 0 \\
\hline
\end{tabular}

* Severe side effects corresponded to a scale three score and required treatment. There were no differences between the groups in the number of patients who developed side effects as determined by the Fisher's exact test.

\section{Discussion}

Quality of analgesia

This is the first double-blind study comparing the analgesic effects of epidural fentanyl and sufentanil combined with very low dose bupivacaine and epinephrine during the first and second stages of labor and delivery. The overall satisfaction scores were comparable in Groups I and II, but this was achieved with statistically but not clinically significant higher pain scores and larger bupivacaine requirements in the patients receiving fentanyl. This difference may have been due to the relatively small (2:1) ratio of fentanyl-to-sufentanil used in this study.

Other investigators ${ }^{11,12}$ have reported very satisfactory and equivalent analgesia using a similar concentration of fentanyl $1.5 \mu \mathrm{g} \cdot \mathrm{ml}^{-1},{ }^{11}$ or $2.5 \mu \mathrm{g} \cdot \mathrm{ml}^{-1},{ }^{12}$ and a substantially lower concentration of sufentanil 0.25 $\mu \mathrm{g} \cdot \mathrm{ml}^{-1}, 11,12$ than we employed (fentanyl to sufentanil ratios of 5:1 and 10:1). However, these studies used bupivacaine $0.125 \%{ }^{11}$ or $0.0625 \%,,^{12}$ concentrations five and ten times greater than we employed and it is possible that the opioids contributed relatively little to the overall quality of analgesia in their groups. Based on our data in this and previous reports,, 10 epidural infusions containing either fentanyl $2-3 \mu \mathrm{g} \cdot \mathrm{ml}^{-1}$ or sufentanil $0.8-1 \cdot \mu \mathrm{g} \cdot \mathrm{ml}^{-1}$ together with bupivacaine $0.01-0.015 \%$ and epinephrine $0.5-1 \mu \mathrm{g} \cdot \mathrm{ml}^{-1}$ at a rate of 12-16 $\mathrm{ml} \cdot \mathrm{hr}^{-1}$ provide satisfactory analgesia in obstet- 
ric patients. Since the epidural infusion rates used in this study were patient-determined, the finding that they chose a ratio of fentanyl to sufentanil of 2.5:1 supports the approximate equianalgesic effect of the two drug regimens. This ratio is very similar to the ratio of $2.6: 1$ that we found in our previous study ${ }^{10}$ which compared the ability of fentanyl and sufentanil combined with very low dose bupivacaine and epinephrine, and administered by patient-controlled epidural infusion to provide pain relief after caesarean delivery. Administration of appreciably larger doses of 2-chloroprocaine, than were used as the test dose in this study, have been shown to decrease the effectiveness of epidural analgesia with some opioids given as a bolus. ${ }^{15}$ It is unlikely that the small dose of 2-chloroprocaine used here influenced the efficacy of continuous epidural fentanyl or sufentanil.

\section{Conduct of labour and delivery}

The durations of the first and second stages of labour did not differ among the groups. The obstetrical staff had control over several key decisions determining outcome measures of labour and delivery. The decision to end the infusion was based on their assessment of the progress of labour and of the patient's expulsive efforts. The obstetrician also determined the mode of delivery i.e., natural, instrumental or operative. Vertommen et al. ${ }^{16}$ reported that the addition of sufentanil $(10-30 \mu \mathrm{g})$ to epidural bupivacaine $(0.125 \%)$ and epinephrine $(1: 800,000)$ decreased the incidence of instrumental delivery and attributed this to the lower bupivacaine dose used. The observed incidence of instrumental delivery in our study, yaried from $6-10 \%$ between the groups, and is much lower than that reported by Vertommen et al. ${ }^{16}$ or by Chestnut et al. ${ }^{1}$ in patients receiving sufentanil or fentanyl with bupivacaine $0.125 \%$ or $0.0625 \%$, respectively. However, our combined rate of Caesarean delivery $(24 \%)$ was higher than in the above mentioned studies ${ }^{1,21}$ but comparable to the national USA rate of $25 \%$ in $1988 .{ }^{17}$ Caesarean and instrumental delivery rate comparisons among studies should be done with caution, however, since many factors such as effects of physician training in the use of instrumental deliveries, physician age and the use of electronic fetal monitoring differ from one study to another.

\section{Neonatal outcome}

The mean doses of fentanyl (205 $\mu \mathrm{g}$ ) or sufentanil (86 $\mu \mathrm{g}$ ) used in this study did not adversely affect the Apgar scores or lead to cyanosis or respiratory depression in any newborn. The durations of the first and second stages of labour for Group I $(15.7 \pm 1.6 \mathrm{hr}$; $1.4 \pm 1.2$ hr., respectively) did not differ from that of Group II
$(13.8 \pm 1.2 \mathrm{hr}$; $1.4 \pm 1.0 \mathrm{hr}$., respectively). The mean maternal and umbilical vein plasma concentrations in our study were $<0.3 \mathrm{ng} \cdot \mathrm{ml}^{-1}$ for fentanyl and $\leq 0.11$ $\mathrm{ng} \cdot \mathrm{ml}^{-1}$ for sufentanil and are similar to those reported in other studies. ${ }^{5,7,18}$ The mean umbilical plasma concentration of fentanyl observed was $<1.0 \mathrm{ng} \cdot \mathrm{ml}^{-1}$ which is reported to be associated with neonatal respiratory depression. ${ }^{19}$ Our data do not apply to neonates of highrisk parturients. No data are available for the umbilical plasma concentration of sufentanil associated with respiratory depression in neonates.

\section{Conclusion}

Epidural opioid infusion with low dose bupivacaine and epinephrine achieved a high patient satisfaction in both groups without serious maternal or neonatal side effects. Patients receiving sufentanil $1 \mu \mathrm{g} \cdot \mathrm{ml}^{-1}$ required less total bupivacaine than those receiving fentanyl 2 $\mu \mathrm{g} \cdot \mathrm{ml}^{-1}$ and substantially fewer requested a bupivacaine rescue dose.

\section{Acknowledgement}

The authors thank Ms. Barbara Viets for the preparation of this manuscript.

\section{References}

1 Chestnut DH, Owen CL, Bates JN, Ostman LG, Choi WW, Geiger $M W$. Continuous infusion epidural analgesia during labor: a randomized, double-blind comparison of $0.0625 \%$ bupivacaine/ $0.0002 \%$ fentanyl versus $0.125 \%$ bupivacaine. Anesthesiology 1988; 68: 754-9.

2 Breen TW, Shapiro T, Glass B, Foster-Payne D, Oriol NE. Epidural anesthesia for labor in an ambulatory patient. Anesth Analg 1993; 77: 919-24.

3 Cohen SE, Tan S, Albright GA, Halpern J. Epidural fentanyl/bupivacaine mixtures for obstetric analgesia. Anesthesiology 1987; 67: 403-7.

4 Murphy JD, Henderson K, Bowden MI, Lewis M, Cooper $G M$. Bupivacaine versus bupivacaine plus fentanyl for epidural analgesia: effect on maternal satisfaction. BMJ 1991; 302: 564-7.

5 Gambling DR, Huber CJ, Berkowitz J, et al. Patientcontrolled epidural analgesia in labour: varying bolus dose and lockout interval. Can J Anaesth 1993; 40: 211-7.

6 van Steenberge A, Debroux HC, Noorduin H. Extradural bupivacaine with sufentanil for vaginal delivery. A double-blind trial. Br J Anaesth 1987; 59: 1518-22.

7 Phillips $G$. Continuous infusion epidural analgesia in labor: the effect of adding sufentanil to $0.125 \%$ bupivacaine. Anesth Analg 1988; 67: 462-5.

8 Cohen S, Amar D, Pantuck CB, Pantuck EJ, Weissman AB. Adverse effects of epidural $0.03 \%$ bupivacaine during 
analgesia after cesarean section. Anesth Analg 1992; 75 : 753-6.

9 Cohen S, Amar D, Pantuck CB, et al. Epidural patientcontrolled analgesia after cesarean section: buprenorphine- $0.015 \%$ bupivacaine with epinephrine versus fentanyl-0.015\% bupivacaine with and without epinephrine. Anesth Analg 1992; 74: 226-30.

10 Cohen S, Amar D, Pantuck CB, et al. Postcesarean delivery epidural patient-controlled analgesia. Fentanyl or sufentanil? Anesthesiology 1993; 78: 486-91.

11 Loftus $J R$, Hill $H$, Cohen S. Epidural fentanyl and sufentanil with bupivacaine for labor: maternal and neonatal effects. Anesthesiology 1991; 75: A856.

12 Russell $R$, Reynolds $F$. Epidural infusions for nulliparous women in labor. A randomised double-blind comparison of fentanyl/bupivacaine and sufentanil/bupivacaine. Anaesthesia 1993; 48: 856-61.

13 Michiels $M$, Hendriks $R$, Heykants $J$. A sensitive radioimmunoassay for fentanyl. Plasma level in dogs and man. Eur J Clin Pharmacol 1977; 12: 153-8.

14 Michiels $M$, Hendriks $R$, Heykants $J$. Radioimmunoassay of the new opiate analgesics alfentanil and sufentanil. Preliminary pharmacokinetic profile in man. J Pharm Pharmacol 1983; 35: 86-93.

15 Grice SC, Eisenach JC, Dewan DM. Labor analgesia with epidural bupivacaine plus fentanyl: enhancement with epinephrine and inhibition with 2-Chloroprocaine. Anesthesiology 1990; 72: 623-8.

16 Vertommen JD, Vandermeulen E, Van Aken $H$, et al. The effects of the addition of sufentanil to $0.125 \%$ bupivacaine on the quality of analgesia during labor and on the incidence of instrumental deliveries. Anesthesiology 1991; 74: 809-14.

17 Taffel SM, Placek PJ, Moien M. 1988 US Cesarean section rate at 24.7 per 100 births - a plateau? (Letter). $\mathrm{N}$ Engl J Med 1990; 323: 199-200.

18 D'Athis $F$, Macheboeuf $M$, Thomas $H$, et al. Epidural analgesia with a bupivacaine-fentanyl mixture in obstetrics: comparison of repeated injections and continuous infusion. Can J Anaesth 1988; 35: 116-22.

19 Hertzka RE, Gauntlett IS, Fisher DM, Spellman MJ. Fentanyl-induced ventilatory depression: effects of age. Anesthesiology 1989; 70: 213-8. 